\title{
APLIKASI KAMUS HEWAN DAN TUMBUHAN BERBASIS ANDROID
}

\author{
Nadya Deandra Yohana ${ }^{1}$, Dwi Purnomo ${ }^{2}$ \\ yohanadeandra@gmail.com,purnomo@widyagama.ac.id \\ Universitas Widyagama Malang
}

\begin{abstract}
Currently the development of information very rapidly along with the advancement of information technology where almost all over the world using this technology facility. One technology to facilitate communication and information, namely the creation of mobile applications. Indonesia is an archipelago country with a rich diversity of flora and fauna. In each province there is a flora and fauna that is characteristic of the area. Flora and Fauna is a province in the Indonesian identity.

In an attempt to introduce the diversity of Flora and Fauna in Indonesia by utilizing computer technology, it is at present a dictionary-shaped mobile application to facilitate searching for information about the types of flora and fauna in Indonesia

Applications Flora and Fauna Indonesia Dictionary Android- based aims to introduce and provide information about the diversity of the types of Flora and Fauna in Indonesia, this application is addressed to the society, especially for children and students as a means of education or learning about the flora and fauna. Features in this dictionary application displays about the scientific name, profile, as well as information about the flora and fauna in Indonesia.
\end{abstract}

Intisari- Saat ini perkembangan informasi yang sangat pesat seiring dengan kemajuan teknologi informasi dimana hampir seluruh dunia menggunakan fasilitas teknologi ini. Salah satu teknologi untuk memfasilitasi komunikasi dan informasi, yaitu pembuatan aplikasi mobile. Indonesia merupakan negara kepulauan dengan keanekaragaman flora dan fauna. Di setiap provinsi ada flora dan fauna yang merupakan karakteristik dari daerah. Flora dan Fauna adalah sebuah provinsi di identitas Indonesia.

Dalam upaya untuk memperkenalkan keragaman Flora dan Fauna di Indonesia dengan memanfaatkan teknologi komputer, itu adalah saat ini aplikasi mobile kamus berbentuk memfasilitasi mencari informasi tentang jenis-jenis flora dan fauna di Indonesia.

Aplikasi Flora dan Fauna Indonesia Kamus Android berbasis tujuan untuk memperkenalkan dan memberikan informasi tentang keragaman jenis Flora dan Fauna di Indonesia, aplikasi ini ditujukan kepada masyarakat, terutama bagi anak-anak dan siswa sebagai sarana pendidikan atau belajar tentang Tumbuhan dan Hewan. Fitur dalam menampilkan aplikasi kamus tentang nama ilmiah, profil, serta informasi tentang flora dan fauna di Indonesia.

Kata Kunci- Kamus, Flora dan Fauna, informasi, nama ilmiah, belajar

\section{PENDAHULUAN}

Kehidupan manusia tidak lepas dengan adanya berbagai macam makhluk hidup lainnya yang berada di alam semesta seperti hewan dan tumbuhan dimana itu semua terdapat dan bisa kita pelajari dalam dunia biologi, selain kita bisa mempelajari seputar siklus hidup, jenis serta ciri-ciri dari makhluk hidup tersebut kita juga bisa mempelajari nama latin makhluk hidup tersebut untuk mengetahui penggolongan ciri dan jenisnya berdasarkan nama latinnya, dalam bahasa ilmiah atau bisa disebut dengan bahasa latin. Tetapi dalam beberapa kasus para siswa sering kali mengalami kesulitan ketika diharuskan untuk mengenal bahkan menghafal nama ilmiah dari hewan dan tumbuhan tersebut. Teknologi mobile merupakan bagian yang familiar dalam kehidupan masyarakat Indonesia.

Dalam mempelajari tentang nama ilmiah hampir semua masyarakat dan para pelajar pada umumnya tidak menggunakan media bantu, karena memang media yang tersedia kebanyakan hanya berupa buku dan itu tidak semua orang mempunyai buku tersebut. Dan ketidaktersediaan media teknologi informasi yang dapat dengan cepat memberikan informasi tentang nama ilmiah hewan atau tumbuhan membuat para siswa semakin sulit dalam mempelajari nama ilmiah tersebut. Kekurangan lainnya dalam mempelajari nama ilmiah hewan ataupun tumbuhan adalah tidak adanya gambar-gambar hewan dan tumbuhan beserta tata namanya. Tidak adanya media yang mendukung inilah semakin membuat para siswa kesulitan untuk mempelajari nama ilmiah hewan dan tumbuhan dan memperoleh informasi tentang bahasa ilmiah dari hewan dan tumbuhan secara cepat dan akurat.

\section{TINJAUAN PUSTAKA}

\section{A. Perangkat Lunak}

Perangkat lunak merupakan serangkaian instruksi dengan aturan tertentu yang mengatur operasi perangkat keras (Sutanta \& Edhy, 2005)

Perkembangan perangkat keras yang begitu terasa, berefek pula kepada perkembangan dari perangkat lunak, ini dibuktikan

dengan semakin majunya bidang teknologi informasi baik yang berupa perangkat keras maupun perangkat lunak. Guna untuk mengetahui kualitas dari perangkat lunak tersebut, Dr. Richardus Eko Indrajit dalam bukunya Manajemen Sistem Informasi dan

Teknologi Informasi mengemukakan tentang tiga kriteria untuk mengetahui kualitas dari perangkat lunak tersebut, yaitu :

1. Memenuhi kebutuhan pemakai, yaitu jika perangkat lunak tidak dapat memenuhi kebutuhan pemakai tersebut, maka 
perangkast lunak tersebut dikatakan tidak atau kurang memiliki kualitas.

2. Memenuhi standar pengembangan software, yaitu jika cara pengembangan software tidak mengikuti metodologi standar,

maka hampir dapat dipastikan bahwa kualitas yang baik akan sulit atau tidak tercapai.

3. Memenuhi sejumlah kriteria implisit, yaitu jika salah satu kriteria implisit tersebut tidak dapat dipenuhi, maka perangkat lunak yang bersangkutan tidak memiliki kualitas yang baik.

\section{B. Kamus}

Kamus yaitu buku acuan yang memuat kata dan ungkapan yang biasanya disusun menurut abjad berikut keterangan tentang maknanya. Kamus adalah sejenis buku rujukan yang menerangkan makna kata-kata. Kamus berfungsi untuk membantu seseorang mengenal perkataan baru. Selain menerangkan maksud kata kamus juga mungkin mempunyai pedoman sebutan, asal usul (etimologi) sesuatu perkataan dan juga contoh penggunaan bagi sesuatu perkataan. Untuk memperjelas kadang kala terdapat juga ilustrasi didalam kamus. Kata kamus diserap dari bahasa Arab qamus, dengan bentuk jamaknya qawamis. Kata Arab itu sendiri berasal dari kata Yunani okeanos yang berarti lautan. Sejarah kata itu jelasmemperlihatkan mana dasar yang terkandung dalam kata kamus, yaitu wadah pengetahuan, khusunya pengetahuan bahasa, yang tidak terhingga dalam dan luasnya. Dalam pengertian lain, Kamus adalah buku acuan yang memuat kata dan ungkapan, biasanya disusun menurut abjad beserta penjelasan tentang makna dan pemakainya (Kamus Besar Bahasa Indonesia).

\section{Hewan}

Hewan atau binatang atau margasatwa atau satwa saja adalah kelompok organisme yang diklasifikasikan dalam kerajaan Animalia atau Metazoa, adalah salah satu dari berbagai makhluk hidup yang terdapat di alam semesta. Hewan dapat terdiri dari satu sel (uniselular) atau pun banyak sel (multiselular). Semua hewan merupakan organisme heterotrof

\section{Tumbuhan}

Tumbuhan adalah organisme benda hidup yang terkandung dalam alam Plantae. Biasanya, organisme yang menjalankan proses fotosintesis adalah diklasifikasikan sebagai tumbuhan. Tumbuhan memerlukan cahaya matahari untuk menjalani proses fotositesis.

Tumbuhan merangkumi semua benda hidup yang mampu menghasilkan makanan dengan menggunakan klorofil untuk menjalani proses fotosintesis dan menghasilkan kanji. Sel tumbuhan berbeda dengan sel hewan, dalam beberapa segi sel tumbuhan mempunyai dinding sel

\section{E. Sistem Operasi Android}

Sistem operasi Android adalah sebuah sistem operasi untuk perangkat mobile berbasis linux yang mencakup sistem operasi, middleware, dan aplikasi (Safaat \& Nazruddin, 2011). Platform android bermula dari nama sebuah perusahaan yang berkecimpung di dunia IT \& Communication khususnya bergerak dalam bidang perangkat lunak dengan nama Android Inc. yang kemudian seluruh sahamnya dibeli oleh perusahaan raksasa yaitu Google Inc., setelah itu dibentuklah Open Handset Alliance, yaitu konsorsium dari 34 perusahaan piranti keras, piranti lunak dan telekomunikasi termasuk di dalamnya yaitu : Google, HTC, Intel, Motorola, Qualcomm, T - Mobile dan Nvidia. Adapaun ikon dari sistem operasi Android ini sering disebut juga dengan sebutan robot ijo.

Android adalah sistem operasi untuk telepon seluler yang berbasis Linux. Jadi Android itu adalah sebuah OS untuk perangkat mobile yang dibuat oleh Google berdasarkan modifikasi dari Kernel Linux. Android menyediakan platform terbuka bagi para pengembang untuk menciptakan aplikasi mereka sendiri dan digunakan untuk bermacam perangkat mobile. Awalnya, Goole Inc. membeli Android Inc, pendatang baru yang membuat piranti lunak untuk ponsel. Kemudian untuk mengembangkan Android, dibentuk OpenHhandset Alliance, konsursium dari 34 perusahaan hardware, software, dan telekomunikasi, termasuk Google, HTC, Intel, Motorola, Qualcomm, T-Mobile, dan Nvidia.

\section{F. Java}

Java dalam ilmu komputer, merupakan bahasa pemrograman berorientasi objek yang diperkenalkan pada tahun 1995 oleh Sun Microsystem Inc., yang saat Java diciptakan, dipimpin oleh James Gosling (Nugroho \& Adi, 2008). Bahasa pemrograman java tercipta berawal dari sebuah perusahaan Sun Microsystem yang ingin membuat sebuah bahasa pemrograman yang dapat berjalan di semua device tanpa harus terikat oleh platform yang digunakan oleh device tersebut, terlaksanalah sebuah proyek yang dipelopori oleh Patrick Naughton, James Gosling, Mike Sheridan dan Bill Joy pada tahun 1991,maka terciptalah bahasa pemrograman java yang awalnya bernama Oak".

Java adalah sebuah teknologi dimana pada teknologi tersebut mencakup java sebagai bahasa pemrograman yang memiliki sintaks dan aturan pemrograman tersendiri, juga mencakup java sebagai platform dimana teknologi ini memiliki virtual machine dan library yang diperlukan untuk menulis dan menjalankan program yang ditulis dengan bahasa pemrograman java (Rickyanto, 2003).

\section{ANALISIS \& PERANCANGAN}

\section{A. Analisis}

Tahap analisis sistem dilakukan setelah tahap perancanaan sistem dan sebelum tahap desain sistem. Analisis sistem (system analysis) adalah penguraian dari suatu sistem informasi yang utuh kedalam bagian-bagian atau komponen komponennya dengan maksud untuk mengidentifikasikan dan mengevaluasi permasalahan-permasalahan, kesempatankesempatan, hambatan-hambatan yang terjadi dan kebutuhankebutuhan yang diharapkan sehingga dapat diusulkan perbaikan-perbaikannya.

\section{B. Analisis SWOT}

Analisis SWOT adalah metode perencanaan strategis yang digunakan untuk mengevaluasi kekuatan (strengths), kelemahan (weakness), peluang (opportunities), dan ancaman (threats) dalam suatu proyek atau suatu spekulasi bisnis. Keempat faktor itulah yang membentuk akronim SWOT (strengths, weakness, opportunities dan threats). 


\section{Analisis Kebutuhan Sistem}

Dalam mempermudah analisis sistem untuk menentukan keseluruhan kebutuhan secara lengkap, maka analisis membagi kebutuhan sistem menjadi dua jenis yaitu analisis kebutuhan fungsional dan analisis kebutuhan non fungsional.

\section{Analisis Kelayakan Sistem}

Analisis ini di gunakan untuk menentukan apakah mengembangkan aplikasi ini dapat diteruskan atau tidak. Ini dilakukan agar sistem baru tersebut dapat benar-benar bermanfaat.

\section{E. Perancangan Sistem}

Setelah tahap analisis dilakukan, di dapatkan gambaran dengan jelas apa yang harus dikerjakan. Tahap selanjutnya yaitu memikirkan bagaimana membentuk sistem tersebut. Tahap ini disebut dengan Perancangan Sistem. Tahap perancangan sistem dilakukan oleh analis sistem dan personil-personil teknik lainnya.

\section{IMPLEMENTASI DAN PEMBAHASAN}

\section{A. Implementasi}

Implementasi merupakan tahapan setelah melakukan analisis dan perancangan sistem pada siklus rekayasa perangkat lunak dimana aplikasi siap dioperasikan pada siklus keadaan yang sebenarnya sehingga dari sini akan diketahui apakah program atau aplikasi atau sistem yang telah dibuat benar-benar dapat menghasilkan keluaran yang sesuai dengan tujuan yang diinginkan.

\section{B. Implementasi User Interface}

Dalam aplikasi Kamus flora fauna Indonesia berbasis Android ini terdiri dari beberapa halamam anatamuka (interface) yaitu SplashScreen, Menu Utama, Menu Kamus FF, Menu Cari, Menu Translate, Menu Gallery, dan Menu About.

\section{Interface Halaman Splash Screen}

Halaman Splash Screen merupakan halaman yang pertama kali muncul saat aplikasi kamus flora fauna Indonesia ini dijalankan, halaman ini muncul ketika user mengakses aplikasi ini dalam handphone.

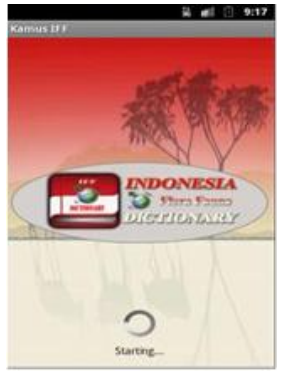

Gambar 1 Tampilan Halaman Splash Screen

\section{Interface Halaman Menu Utama}

Halaman Menu Utama merupakan halaman yang muncul setelah halaman splash screen dieksekusi. Pada halaman ini terdapat empat fitur menu pilihan yaitu menu kamus ff, menu gallery, menu about, dan menu exit.

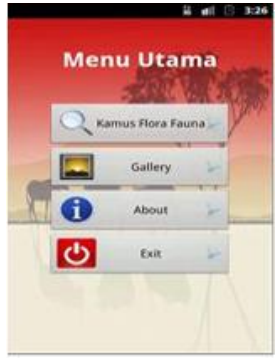

Gambar 2 Tampilan Halaman Menu Utama

\section{E. Interface Halaman Menu Kamus Cari}

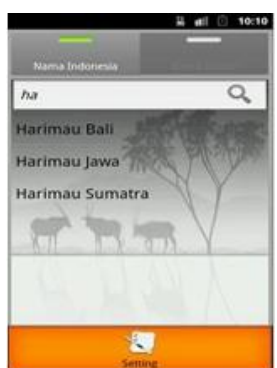

Gambar 3 Tampilan Halaman Menu Kamus Cari

\section{F. Interface Menu Setting}

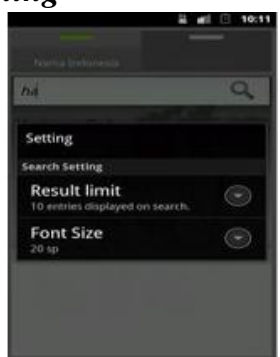

Gambar 4 Tampilan Halaman Setting

\section{G. Interface Halaman Menu Translate}

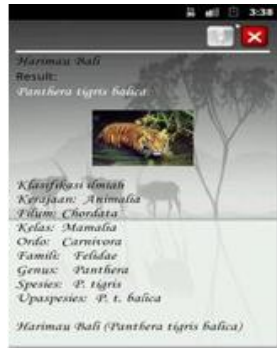

Gambar 5 Tampilan Halaman Menu Translate

\section{KESIMPULAN DAN \\ SARAN}

\section{A.Kesimpulan}

Kesimpulan yang dapat diambil setelah beberapa tahapan dalam menyelesaikan Aplikasi Kamus Flora Fauna Indonesia ini, antara lain:

1. Aplikasi Kamus flora fauna Indonesia berbasis android ini bisa dapat menterjemahkan nama Indonesia ke nama ilmiah atau sebaliknya, menampilkan gambar dan informasi tentang flora fauna tersebut.

2. Aplikasi Kamus flora fauna Indonesia berbasis android ini bisa menjadi media pembelajaran dalam 
mengenalkan keanekaragaman flora dan fauna di Indonesia.

\section{B. Saran}

Pada penulisan skripsi ini tentu masih terdapat banyak kekurangan, yang mungkin dapat disempurnakan lagi penelitian berikutnya. Agar aplikasi dapat menjadi lebih sempurna, terdapat beberapa saran yang dapat di pergunakan diantaranya :

1. Ditambahkan data jenis flora dan fauna dari luar Indonesia atau seluruh dunia, agar lebih kompleks dalam pembahasannya.

2. Ditambahkan fitur link, agar dapat mempermudah mencari informasi secara langsung dan efisien.

3. Dilengkapi fitur pencarian flora fauna dengan filter provinsi yang terdapat di Indonesia.

4. Dilengkapi fitur pencarian lokasi tempat-tempat keberadaan flora dan fauna tersebut.

\section{UCAPAN TERIMA KASIH}

Penulis mengucapkan terima kasih kepada Allah SWT, Ayah, Ibu, rekan-rekan yang telah memberikan dukungan moril dan materil kepada penulis dan untuk pembimbing yang telah memberikan pengarahan, fikiran, waktu dan tenaganya selama proses bimbingan menyelesaikan tugas akhir.

\section{Referensi}

[1] Sutanta, \& Edhy. (2005). Pengantar Teknologi Informasi. Yogyakarta: Graha Ilmu.

[2] Safaat, Nazruddin (2011), Pemrograman Aplikasi Mobile Smartphone danTablet PC Berbasis Android, Informatika, Bandung.

[3] Nugroho, Adi (2008), Pemrograman Java Menggunakan IDE Eclipse

Callisto, Andi Offset, Yogyakarta.

[4] Al Fatta, Hanif. 2007. Analisis \& Perancangan Sistem Operasi untuk Keunggulan

[5] Bersaing Perusahaan Dan Organisasi Modern. Yogyakarta: Penerbit Andi Offset

[6] Siregar, Ivan Michael. 2011. Membongkar Berbagai Sourcode Aplikasi Android. Gramedia Yogyakarta.

[7] Rickyanto, Isak (2003), Dasar Pemrograman Berorientasi Objek dengan Java 2 JDK 1.4, Andi Offset, Yogyakarta

[8] Rachel (2012). "Pengertian android, apa itu android". Sumber:http://www.updatekeren.com/2012/07/pengertianandroid-apa-itu- android.html

[9] Wahyudi, Andri (2012). Perancangan Aplikasi Ensiklopedia Pengenalan Hewan dan Habitatnya Menggunakan Macromedia. 